\title{
Product LifeCyCle EXPERIENCE FOR Pre-University STUDENTS THROUGH A HOVERCRAFT COMPETITION
}

\author{
Debbie Leiter ${ }^{1}$, Patty Whitehill ${ }^{1}$, Larry Leiter ${ }^{1}$, Rae-Lynn Rempel ${ }^{2}$, Bill Noakes ${ }^{3}$, \\ Dario Schor ${ }^{4}$, Andres Chapman ${ }^{5}$, Jeffrey Couch ${ }^{3}$,Brad Wallin ${ }^{6}$, Janet Premak, \\ John Chaput ${ }^{l}$, Jenna Biegun ${ }^{l}$, and Alvina Penner ${ }^{l}$ \\ ${ }^{1}$ Centre of Excellence Initiative, Canadian Manufacturers \& Exporters, Winnipeg, MB, Canada \\ ${ }^{2}$ Winnipeg Technical College, Winnipeg, MB, Canada \\ ${ }^{3}$ Red River College, Winnipeg, MB, Canada \\ ${ }^{4}$ Faculty of Engineering, ${ }^{7}$ University of Manitoba, Winnipeg, MB, Canada \\ ${ }^{5}$ Boeing Canada, Winnipeg, MB, Canada, \\ ${ }^{6}$ Wallin Industries, Winnipeg, MB, Canada, \\ debbie.leiter@cme-mec.ca,dschor@ece.umanitoba.ca
}

\begin{abstract}
The Canadian Manufacturers and Exporters Discovery Program is an annual competition where teams of high school students compete to design, build, and test a remote control hovercraft. The competition exposes students to the manufacturing process, from research and development, through to the product launch. Preuniversity teams from across Manitoba compete to build the hovercraft, write a business plan, and present their work to a panel of judges from academia and industry. The winning teams receive scholarships for postsecondary studies.

This paper describes the Discovery Program hovercraft competition and lessons learned from the first four years of the program.
\end{abstract}

Keywords: Design competition; pre-university outreach.

\section{INTRODUCTION}

The Canadian Manufacturers and Exporters (CME) introduced the annual Discovery Program in 2008 to provide high school students with hands-on experience in the manufacturing process. The program offers students an opportunity to learn about Engineering from first-hand participation in the (i) engineering design process and manufacturing processes required to build the remotelycontrolled hovercraft, (ii) project management skills to help manage secure and manage funds while scheduling activities carefully, (iii) exposure to the full product lifecycle by going from paper designs to a finish model presented to a panel of academic and industry representatives, and (iv) entrepreneurial skills that empower students to take chances, innovate, and work towards the goal. Furthermore, the program promotes the engineering design process, manufacturing, project management, product lifecycle, and entrepreneurial skills.
In addition to learning about engineering and manufacturing, the students get hands-on technical skills in (i) electronics (through the implementation of the motors and receives for the hovercraft), (ii) materials (by manufacturing the chassis and skirt for the hovercraft), (iii) communication skills (both within the team as well as the business reports and presentations for the judges), and (iv) teamwork (through their collaboration on a seven month project).

The skills are linked to the Manitoba High School Curriculum with direct connections to Math, Science, and English courses defined in the Discovery Program Teachers Manual [1]. The explicit links help teachers promote the program within their schools and obtain support from administration. Furthermore, through this program, students get valuable experience in the nine essential skills identified by Workplace Education Manitoba that help them obtain both summer employment and part time experience in high school and university.

The program begins each year with invitations to schools to participate. Registration fees are subsidized by CME and include a basic kit of parts for the teams to use (i.e., transmitter with receiver, a micro servo, a battery, two motors, and a battery charger). Teachers and students are encouraged to brainstorm and start working on different ideas for their hovercraft in October before attending the first mentor session on "Design and Planning" hosted by industry experts and students from the University of Manitoba [3]. The focus of this session is on the high level concepts, setting up project milestones, emphasizing the importance of testing, and the iterative nature of the design process. Following the session, the teams spend approximately a month at their schools selecting a practical application for their hovercraft and using that as a driving force to determine their design, internal milestones, and business plan. Prior to the build phase, the second mentor session on 
"Electronics and Materials," is delivered by experts who provide the foundation for the circuits involved and the use of composite materials for the body of the hovercraft. The teams spend the next month designing their hovercrafts and writing their business reports. In January, a semi-final competition is held in which all teams must present their work to the judges, compete through a maneuverability challenge, and a drag race. The top ten teams are invited to refine their designs and compete at the final competition in March of each year.

This paper describes the organization of the Discovery Program and provides a summary of the experience gained over the last four years of the competition.

\section{DISCOVERY PROGRAM}

\subsection{Program Structure}

The timeline for the Discovery Program spans sevenmonths starting in Fall of each academic session when high school classes begin. The overall structure for each month of the competition is described next.

September: The first month is spent forming teams (see Sec. 2.2) and studying the competition rules provided in a Student Manual [2a] and a Teachers Manual [1]. This time also allows teams to research hovercraft designs and the principles of how they work.

October: Due to the lack of experience from both high school students and teachers, CME offers a Mentor Session in early October to help with the design process and project management components of the competition (see Sec. 2.3). Following the mentor session, the teams are able to select a team name, identify purpose for their hovercraft, and begin drafting designs.

November: By mid-November, the teams have an overall idea of what they want to build and are transitioning into the build face. To assist with the process, CME offers a second Mentor Session focused on manufacturing processes and technical skills (see Sec. 2.3). In addition, many teams use this time to secure sponsors and begin drafting the business report for the semi-finals (see Sec. 2.5).

December: During this time, teams try to have a working hovercraft (see Sec. 2.4) and complete the business report to submit to the judges prior to holiday break.

January: The semi-final competitions are held in mid-January at the University of Manitoba where every team gets to present to the judges and showcase their hovercraft to try to advance to the finals.

February: Teams advancing to the finals use this time to refine their design and business plans based on the feedback received from the judges and what they were able to observe during the semi-finals. The business report for the finalists are due at the end of the month.
March: The final competitions are held at the Winnipeg Convention Center during the Canadian Manufacturers and Exporters annual conference.

\subsection{Team Formation}

Every high school in Manitoba is invited to participate in the Discovery Program. Typically, a high school teacher or a small group of teachers will champion the project and promote it to the students to form a single team representing the school. Although the recommended size is 5 to 8 students, some teams have had success with as few as three very dedicated members while others had up to eleven members that included grade 9 students shadowing the senior peers to prepare for future years.

Schools are encouraged to form teams with strong skills in a variety of disciplines like English, Mathematics, Physics, and hands-on skills. This promotes interdisciplinary work that better prepares students for more complex projects [4], while strengthening their team's chances of success in the competition.

\subsection{Mentor Sessions}

The Mentor Sessions were introduced in the $3^{\text {rd }}$ year of the competition to provide additional instruction in specific areas identified through the feedback received from the judges. The sessions are delivered by industry experts and volunteers from the University of Manitoba T-Sat project [3]. Each session runs for three hours and consists of two parts with a short break for refreshments. The students listen to presentations, ask questions, and get a chance to interact with the judges, industry experts, and volunteers to get feedback on their particular hovercrafts.

The first mentoring session focuses on "Design and Planning." The design portion introduces the Engineering Design process by stressing the importance of design on paper, prototyping, testing, and iterating through the process to find the optimal solution. Much of this discussion is lead by Engineering students from the T-Sat project who share their experience with the Canadian Satellite Design Challenge. The planning portion encourages teams to think backwards from the competition deadline and estimate how long each task will take, thus helping them coordinate their activities and allocate their resources optimally. Timelines, Gantt charts, calendars, and other tools are discussed as a means of tracking progress throughout the project. In addition, this session lends itself to many discussions on teamwork, task allocations, and management to address both the business report, securing sponsors, and designing the hovercraft as parallel tasks.

The theme for the second mentoring session is on "Electronics and Materials." During this session, students learn about composite materials through presentations 
from the Composite Innovation Centre that describe both the properties of different materials as well as the techniques for safely working with them in the schools. The electronics portion focuses on expanding the bare minimum circuits to separate the thrust-fan from the liftfan. Many teams go beyond this to add capabilities to go in reverse in order to improve their maneuverability through the course.

\subsection{Hovercraft Design \& Manufacturing}

The hovercraft design is constrained by four major factors: (i) batteries, (ii) number of fans, (iii) type of transmitter/receiver used, and (iv) physical dimensions. The batteries must by NickelMetal Hydride (NiMH) with a maximum of 11.1 volts each. Lithium Polymer batteries are strictly prohibited as they can be a fire hazard when improperly handled. The limitation in voltage serves as a level playfield for all teams and has shown to be sufficient power to overcome all the obstacles in the track. Some teams may elect to connect more than one battery to power up to a maximum of four fans controlled by the transmitter/receive pair provided by CME. Finally, the hovercrafts much have a maximum width of two feet to fit through the ramps in the track, however, most teams never approach this limit as larger vehicles require more lift fans and thus complicate their designs.

The design of the hovercraft begins with paper sketches on the general shape for the hovercraft and comparisons of different materials to use. The sketches often evolve to a CAD drawing or 3D rendering program such as Google Sketch-Up as shown in Fig. 1. The tools vary depending on availability and expertise available at each school.

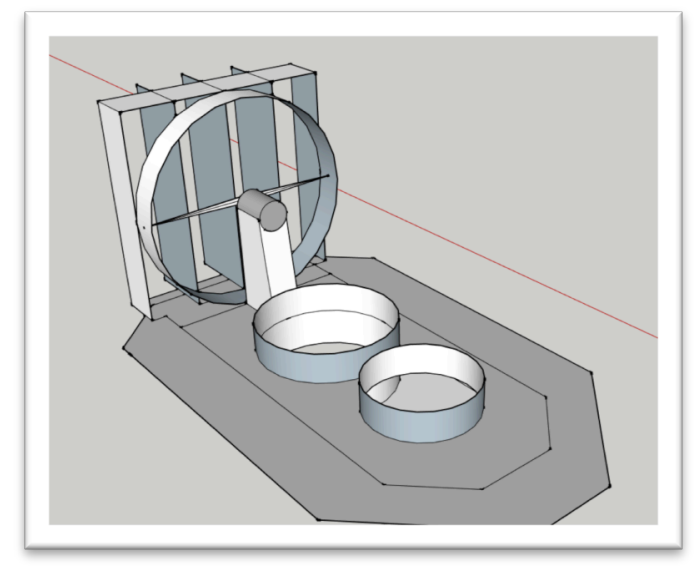

Fig. 1. Sketch of hovercraft design.

The manufacturing phase is often conducted in the school's shop or science laboratories. Depending on the design, some teams elect to build the hovercraft using styrofome cut using the school's CNC machine, while others simplify the process by using cardboard cutouts. Teams interested in composite materials can obtain kits from the Composites Innovation Centre to build a mold and design the chassis out of a light composite material. This is often tested, but seldom used for the final hovercraft as teams often take a few attempts to learn how to use the composites and switch to alternative methods when they realize they are running out-of-time. However, the process serves as a valuable learning experience and the process as well as prototypes are documented in the business reports.

Teams often produce simplified schematics or block diagrams showing how the electronic components are connected in their hovercraft. More advanced teams have analyzed their circuits using oscilloscopes, captured waveforms from their motors, and included additional features such as LEDs and small cameras.

\subsection{Business Report}

The suggested outline for the business report and key components required in each section are as follows:

Overview \& Objectives: This serves as an introduction that identifies the purpose for the hovercraft and key elements that distinguish it from other designs.

Human Resources: This section identifies each team member and their role on the team. Industry sponsors, mentors, teachers, parents, and other collaborators must be recognized for their contributions.

Work Plan: The work plan provides the schedule for the project showing the internal deadlines and actual completion dates. It must identify the design, build, testing, and re-work phases thus emphasizing the topics covered during the first mentor session.

Marketing Plan: This is an optional section that some teams choose to include if the purpose of their hovercraft is for a commercial application. The plans may include projected manufacturing costs, how it can be marketed, and target audience.

Financials: All income and expenses from the project must be documented in this section. This includes registration costs, parts, materials, in-kind contributions, estimates for in-kind expert advise, replacement parts, and other expenses like pizza lunches for the team. Specific examples on proper budgets are provided in the Student Manual to help guide the teams through the process [1].

Design Documentation: This section describes the design and manufacturing process for the hovercraft as well as the problems encountered and how they were overcome.

Conclusion: This section includes the lessons learned, relationship to the school curriculum, and a short reflection on working as a team. The purpose of this section is to get students to think beyond the hovercraft design how the competition impacts their education. 
Recommendations: The final section serves to improve the competition for future years and helps teachers understand elements within their schools that can be improved. The teams are asked to describe what was successful, what they would have done differently, and how they could make the program better.

\subsection{Team Sponsors}

Teams are encouraged to secure sponsors from the community. Sponsors are allowed to provide a maximum of $\$ 250$ to a team as a cash donation, in-kind contribution (expertise or products), or a combination of the two. The costs are used to cover the registration into the competition ( $\$ 40$ per student), additional components purchased by teams, replacement pieces, team T-shirts, and other expenses used to promote team spirit that help teams stand out at the competition.

Since some schools prohibit their students from approaching local companies for sponsorship, teams sometimes offset the costs through bake sales and other school fundraisers.

All sponsors or other sources of income must be recognized by the students in the business plan and acknowledged in the presentation to the judges.

\subsection{Competition \& Judging}

Every school that enters the competition is invited to participate in the semi-finals at the University of Manitoba. From there, ten finalists are selected to advance to the next round. The scoring is divided into $50 \%$ for design and performance of the hovercraft, $20 \%$ for the business report, and $30 \%$ for problem solving and teamwork.

The judging process begins two weeks prior to the semi-finals or finals when the teams submit their business reports. This allows the judges to carefully read all the reports and assign scores using a predefined rubric that looks at all the requirements described in Sec. 2.5.

At the competition, teams get 15 minutes to present their hovercraft to the judges. PowerPoint presentations, videos, and other multimedia are allowed at the finals only to keep the competition on schedule. All team members must participate in the presentation or face point deductions. The presentations are followed by a few questions from the judges on elements of the business report or the hovercraft design. Often, when the hovercraft fails to complete the track the judges will ask what the students think the problem is, how would they fix it if they had more time, and what they would have done differently to avoid the problem.

Following the presentation, the teams test the maneuverability of their hovercraft on the track shown in Fig. 2. The track consists of a number of turns, two ramps, and a small pool of water to ensure their prototype can travel on all terrains. Finally, teams participate in a drag race carrying a $395 \mathrm{~g}$ load.

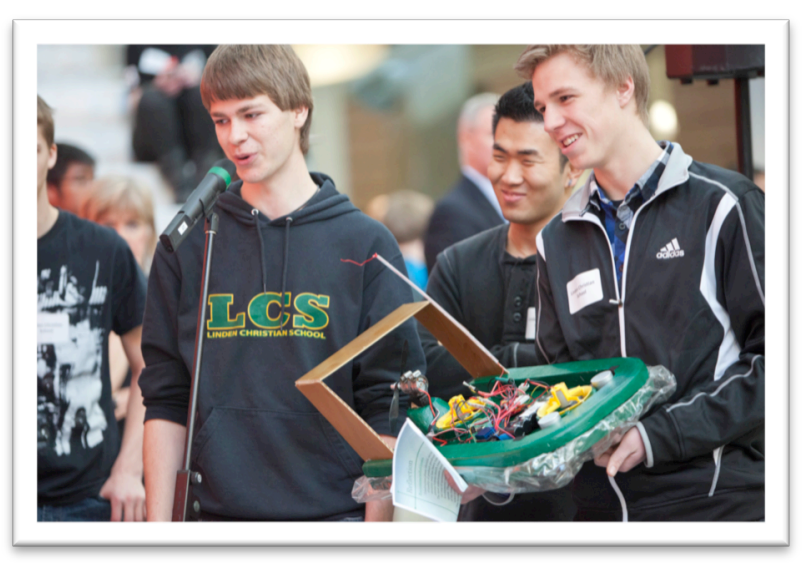

Fig. 2. Students presenting hovercraft to the judges.

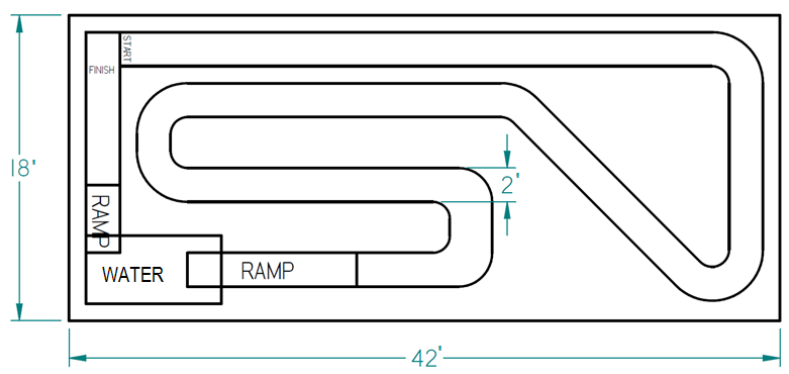

Fig. 3. 2011-2012 track for hovercraft competition.

The panel of five judges includes two academics, two industry representatives, and one CME employee. The academics and industry judges are further divided into one business and one engineering/manufacturing background, thus providing a well-balanced group capable of focusing on different elements of the competition.

\subsection{Winners \& Honorable Mentions}

The top three teams receive scholarships to postsecondary institutions in Manitoba. Five additional honorable mentions are selected for the highest scores in the categories of (i) business report, (ii) maneuverability, (iii) speed, (iv) resources and innovation, and (v) team spirit.

\section{CONCLUDING REMARKS}

The Discovery Program has grown from 12 teams during the first two years to 22 teams in the 2011-2012 academic session. In the first four years, 20 scholarships have been granted to a pool of 69 eligible students that have placed in the top teams in the competition as shown 
in Table 1. It is important to note that the teams are composed of grade 9-12 students, so some of the eligible members can delay their scholarships for a number of years until they commence their post-secondary education.

Table 1. Scholarships awarded per year.

\begin{tabular}{|l|l|l|}
\hline Year & Students Eligible & Scholarships Claimed \\
\hline 2008 & 17 & 3 \\
\hline 2009 & 18 & 11 \\
\hline 2010 & 14 & 2 \\
\hline 2011 & 20 & 4 \\
\hline Total: & 69 & 20 \\
\hline
\end{tabular}

In addition, the program has evolved to provide a larger support infrastructure to facilitate the learning opportunities for students. The mentor sessions were added as a face-to-face opportunity to get training as well as ask questions to experts. The sessions were complemented with an online forum where students and teachers can ask questions, and video tutorials are being developed for the 2012-2013 academic session to demonstrate specific skills like how to create a Gantt chart or safety precautions for connecting the electronics.

In addition, the program has expanded beyond the hovercraft to include university laboratory tours during the semi-finals and some collaboration with industry to provide tours to schools interested. This exposes students to more advanced projects within the engineering profession.

There are many lessons learned from this competition. Some of the lessons have resulted in more mentoring sessions to explain the operation of the hovercraft. It appears that the mechanical part of the craft is understood and handled, but the electrical and electronics components of the craft are treated as black boxes. Since students at the University of Manitoba run electronics workshops for other students from both the UofM and pre-university institutions [5], it could be beneficial to include the hovercraft students in the workshops. Furthermore, since the UofM provides a non-credit course on ham radio (covering essential elements of the electromagnetic theory and radio operations), the hovercraft students could also be invited to participate in the course in order to learn how the radio control works. The suggested extensions could be used to recruit the students not only to Mechanical \& Manufacturing Engineering, but also to Electrical \& Computer Engineering.
Overall, the program offers students an exposure to design and manufacturing through a hands-on hovercraft design competition. The program provides many opportunities for learning outside the classroom on both technical and communication skills, while also promoting careers in engineering and manufacturing.

\section{Acknowledgements}

Special thanks to the University of Manitoba, Winnipeg Technical College, and Red River College for providing scholarships to the winning teams. Thank you to all the teachers and mentors that spent countless hours working with the students on the day-to-day activities building the hovercraft, drafting the business plan, and preparing for the presentation.

\section{References}

[1] Canadian Manufaturers and Exporters, 2011-2012

Teacher's Resource Manual, 2011, 48 pp.

[2] Canadian Manufaturers and Exporters, 2011-2012 Student Resource Manual, 2011, 28 pp.

[3] Dario Schor, Kane Anderson, Mohammadreza FazelDarbandi, Greg Linton, Matthew Woelk, Cody Friesen, Scott McKay, Katriana Soriano, Chad Stasiuk, Johnson Vilayvanh, Brendan Cade, David Terrazas, Troy Denton, Stephanie Reid, Witold Kinsner, M. D. (Ron) Britton, Dave Weichel, Debbie Leiter, Rob Streimer, Norman Lee, "Preuniversity outreach through a satellite design competition," in Proc. of Canadian Engineering Education Association Conf., CEEA12 (Winnipeg, MB: June 17-20, 2012), 2012, $6 \mathrm{pp}$.

[4] Dario Schor, Kane Anderson, Cody Friesen, Kris Goodmanson, Morgan May, Arash Fazel-Darbandi, Witold Kinsner, M. D. (Ron) Britton, and Malcolm Symonds, "Complex system design exposure thorugh a satellite competition," in Proc. of Canadian Engineering Education Association Conf., CEEA12 (Winnipeg, MB: June 17-20, 2012), 2012, 5 pp.

[5] Dario Schor, Troy Denton, Matthew Sebastian, Matthew Woelk, Frank Serafin, Craig Nemeth, Pawel Glowacki, Kiral Poon, Kane Anderson, Greg Linton, Arash Fazel Darbandi, Witold Kinsner, Allan McKay, Kenneth Biegun, and Udaya Annakkage, "Complementing classroom experience with student-run workshops," in Proc. 2012 Can. Eng. Edu. Assoc. (CEEA) Conference (Winnipeg, MB; June 17-20, 2012) Paper 34, 2012, 5 pp. 